\title{
Los videojuegos como herramienta docente para la historia del cine: el proyecto Gameplaygag
}

\author{
Manuel GARÍN BORONAT \\ Universitat Pompeu Fabra \\ manuel.garin@upf.edu
}

Recibido: $31 / 07 / 2012$

Aceptado: 22/10/2012

\section{Resumen}

El presente artículo se centra en el proyecto pedagógico de audiovisual comparado Gameplaygag. Between Silent Film and New Media (gameplaygag.com), desarrollado durante dos estancias de investigación en la Tokyo University of The Arts y la University of Southern California. El proyecto plantea una nueva forma de enfocar la docencia sobre medios audiovisuales, concretamente sobre la historia del cine, a través de la edición de vídeos online a pantalla partida, que yuxtaponen secuencias cinematográficas con fragmentos de videojuegos, a fin de acercar a los alumnos una serie de conceptos estéticos, históricos y estructurales de modo dinámico e innovador, promoviendo la reapropiación de imágenes en Internet como herramienta docente.

Palabras clave: Comunicación, Cine, Videojuegos, Historia, Educación

\section{Videogames as Educational Tools for Film History: The Gameplaygag Project}

\begin{abstract}
The following essay focuses on the audiovisual education comparative project Gameplaygag. Between Silent Film and New Media (gameplaygag.com), developed during two academic research stays at The Tokyo University of The Arts and The University of Southern California. The project draws upon a new approach to education in audiovisual media, specifically focused on film history, which relies on the online editing of split-screen videos that juxtapose cinematic sequences with certain fragments of videogames, in order to introduce a number of aesthetic, historical and structural concepts to the students in a dynamic and innovative fashion, thus promoting the re-appropriation of images through the Internet as a key didactic tool.
\end{abstract}

Keywords: Communication, Film, Videogames, History, Education

\section{Referencia normalizada}

GARÍN BORONAT, Manuel (2012): "Los videojuegos como herramienta docente para la historia del cine: el proyecto Gameplaygag”. Estudios sobre el mensaje periodístico. Vol. 18, núm. especial octubre, págs.: 425-432. Madrid, Servicio de Publicaciones de la Universidad Complutense.

Sumario: 1. Introducción: audiovisual comparado. 2. Metodología: del cine mudo a los new media. 3. Desarrollo: tres modelos para repensar lo cinematográfico y lo jugable; 3.1. Las etapas primitivas: atracciones y pantallas; 3.2. La estética operacional: del burlesco a los juegos de Super Mario; 3.3. El origen de los géneros audiovisuales: de Fairbanks a los beat'em up. 4. Conclusiones: el cine mudo como herramienta de creación interactiva. 5. Referencias bibliográficas.

\section{Introducción: audiovisual comparado}

En el contexto de la cultura audiovisual contemporánea, enseñar y aprender historia del cine supone una tarea clave para afianzar los conocimientos del alumnado sobre una base sólida, que permita abordar los retos de los new media actuales a partir de los procesos históricos de la imagen en movimiento en el siglo XX. En un hábitat cada vez más híbrido, donde los discursos y las pantallas se dispersan exponencialmente, es fundamental asentar el pensamiento crítico sobre los antecedentes históri- 
cos del medio, con el cine como gran cauce de los imaginarios populares de la comunicación. Para llevar a cabo esa tarea cabe exigir una implicación directa de los docentes -junto a los estudiantes- en la generación de contenido digital. Las nuevas tecnologías han puesto a nuestro alcance herramientas que, como la reapropiación y el remontaje, vinculan el estudio de las imágenes (de sus significados, en suma) con el trabajo directo sobre las mismas: se trata, por tanto, de estudiar los media re-haciéndolos, y plantear experiencias docentes que acerquen las imágenes del pasado a las imágenes del presente.

"The digital remixing of media content makes visible the degree in which all cultural expression builds on what has come before it. Appropriation is understood here as a process by which students learn by taking culture apart and putting it back together again" (Jenkins, 2009a: 55). Las palabras de Henry Jenkins, quizá el autor que más y mejor representa ese take apart / put back together de la cultura académica actual, ponen sobre la mesa un hecho innegable: por primera vez en la historia, el momento presente posibilita que tanto alumnos como profesores manipulen conjuntamente las imágenes (gracias a varias herramientas digitales de reapropiación), poniendo en común las preguntas que suscita el discurso audiovisual. Este artículo se enmarca en ese estado de la cuestión: el aprendizaje de las imágenes del pasado (cine mudo) desde, a partir de y hacia las imágenes del presente (videojuegos). Concretamente, defendemos aquí el uso de imágenes de juegos para re-explicar la historia del cine canónica y, de modo específico, sus etapas primitivas. Sería pretencioso y falaz afirmar que esta idea es algo nuevo, puesto que hay otros ejemplos en el seno de las llamadas New Media Literacies que defienden esta forma de reinterpretar las imágenes del presente para hacer entender las imágenes del pasado (Manovich, 2001: 78). Por tanto, este artículo participa de una corriente académica que ha dado numerosos frutos en el contexto de la academia anglosajona y que da nombre, además, a importantes centros de investigación científica e innovación docente como el Comparative Media Studies del MIT en Boston. Nuestra voluntad es proponer una aportación concreta a ese cauce de pensamiento, centrada en la realización de vídeos a pantalla partida que comparen secuencias de cine mudo y de videojuegos como propuesta educativa.

\section{Metodología: del cine mudo a los new media}

Los primeros videojuegos comparten con el cine de los orígenes una misma primacía de lo visual sobre lo verbal y de lo fragmentario sobre lo argumental, que celebra el potencial lúdico de las imágenes en movimiento, sin diálogos sincrónicos ni grandes corsés narrativos. Ahondar en esos vínculos cine mudo/videojuegos supone el objetivo del proyecto Gameplaygag. Between silent film and new media. Desarrollado durante dos estancias de investigación en la Tokyo University of The Arts y la University of Southern California, el proyecto propone una serie de yuxtaposiciones entre el cine de los orígenes y los primeros videojuegos como vehículo para fomentar el aprendizaje de la gramática audiovisual y la historia del cine en nuevas generaciones de alumnos. La iniciativa promueve un acercamiento proactivo y diferencial a una materia como la historiografía fílmica $-\mathrm{y}$ en concreto el cine mudo- que en ocasiones se explica de modo poco sugerente para el estudiante, incentivando la participación del alumno mediante el visionado crítico, la realización de vídeos y la discusión participativa vía Internet. 
En cuanto a su metodología, uno de los aspectos más relevantes del proyecto es que ha sido precisamente el catedrático Henry Jenkins quien lo ha avalado, al difundirlo en su blog de investigación mientras dirigía el centro Comparative Media Studies del MIT, y al tutorizar más tarde la mencionada estancia en la USC de Los Angeles, donde la investigación se materializó en forma de página web (www.gameplaygag.com). El proyecto se enmarca dentro del ámbito metodológico de las New Media Literacies, pues su objetivo es adaptar el uso de los nuevos medios para repensar la cultura digital, tal y como referencia Jenkins al referirse al mismo: "a series of videos which yuxtapose sequences from early films and early video games $[. .$.$] These videos encourage$ us to look backwards and forwards in time, making comparisons across media, in ways that I find both liberating and illuminating" (Jenkins, 2009b: web). Asimismo, Gameplaygag se ha presentado y exhibido en congresos y exposiciones internacionales en diversas ciudades como Bruselas, Málaga, Paris, Los Angeles, Santiago de Compostela, Yokohama, Girona, Udine o Mulhouse (estas referencias, así como los vídeos y el resto de material de investigación, se encuentran en la mencionada página web).

La metodología de Gameplaygag integra tres ámbitos de trabajo básicos: la selección de determinadas etapas históricas del audiovisual (tanto de la historia del cine canónica como de la emergente historia del videojuego); la comparación simbólica, narrativa y estructural de ejemplos a través de una serie de videos comparados que ilustran sus analogías y diferencias (a pantalla partida en formato vídeo); y por último la discusión crítica de varios conceptos académicos derivados de esas etapas históricas (mediante textos escritos y otros modos de participación on-line). Antes de detallar su desarrollo, cabe dejar claro que el proyecto se encuentra en una fase de implementación temprana, en ese sentido este texto plantea dos itinerarios metodológicos de futuro: por un lado una experiencia piloto a lo largo de una asignatura trimestral y por otro, la puesta en marcha de un proyecto de investigación oficial más amplio, financiado en convocatoria pública, que amplíe el trabajo realizado hasta el momento.

\section{Desarrollo: tres modelos para repensar lo cinematográfico y lo jugable}

Una reflexión de Mary Pickford, una de las primeras grandes actrices del Hollywood mudo, ilustra el origen de nuestro proyecto: "Hubiera sido más lógico que el cine mudo se hubiese desarrollado a partir del sonoro y no al revés" (Pickford en Kerr, 1990: 2). La frase de aquella primera 'novia de América' sorprende por su perspicacia, pues parece invitarnos a repensar la historia del cine $-\mathrm{y}$ sus prolongaciones en animación, televisión o videojuegos- a partir de las formas visuales del cine silente. En ese orden de cosas, las películas mudas debieran haberse producido décadas después del cine sonoro, a modo de depuración formal, como si la renuncia a las posibilidades del sonido - entendido como talkie sobredialogado- fuese un intento de liberación estético y artístico de las propias imágenes. Se trata de una paradoja histórica que conviene recuperar al hablar de cine y juegos, pues ¿en qué estamos pensando al referirnos a lo cinematográfico en los videojuegos? ¿No desafían las películas y juegos "mudos" nuestra noción de lo jugable y lo cinematográfico, sus relaciones y sus códigos de representación? 
Existe una percepción muy extendida, entre el público en general y, específicamente entre los alumnos del Grado en Comunicación Audiovisual, que asocia la presencia de elementos fílmicos dentro de los juegos a las llamadas cutscenes o secuencias cinemáticas, como si esas escenas no-jugables, que suelen limitarse a una planificación perezosa y estereotipada de diálogos manidos, fuesen el único punto de unión entre ambos medios. Estamos ante el tipo de preconcepción histórica (cine $=$ cutscenes) que Gameplaygag quiere desmontar, pues al dar por hecho ese cliché no sólo se reduce la riqueza expresiva y la pluralidad del lenguaje cinematográfico sino que se dejan de lado las etapas "primitivas" de ambos medios. Por el contrario, es bien sabido que el cine mudo y de los orígenes vive hoy una segunda juventud, gracias al trabajo de numerosas filmotecas, a la proliferación de reediciones en DVD y a la intensa actividad que genera en Internet (McKernan, 2007-2012: web). Del mismo modo, la estética retro en los videojuegos, el look 8-bits de arcades y juegos en 2D, resurge actualmente con mucha fuerza en la industria, con exitosos ejemplos como Braid (2008), Limbo (2010), N (2005), Super Meat Boy (2010), o Fez (2012).

Luego, si tanto el cine mudo como los primeros videojuegos siguen hoy reinventándose, ¿por qué no comparar y yuxtaponer algunos de sus modelos canónicos? El desarrollo de Gameplaygag se centra, pues, en tres ámbitos históricos, estéticos y formales de ambos medios: en primer lugar, una discusión de su morfología primitiva partiendo del cine de los orígenes, que compara ejemplos de la obra del cineasta español Segundo de Chomón con fragmentos de arcades; en segundo lugar, un análisis de la estética operacional propia de la imagen en movimiento, cotejando las estructuras visuales del cine cómico mudo con las del videojuego de plataformas; y finalmente, un estudio de géneros audiovisuales centrado en el cine de aventuras y sus equivalentes interactivos.

\subsection{Las etapas primitivas: atracciones y pantallas}

Según ha demostrado J. M. Minguet, al analizar la obra de Segundo de Chomón, el cine de los orígenes se distinguía por la multiplicidad, el mestizaje y la cohabitación de diferentes maneras de entender el espectáculo, que constituían el oficio del cine, que bebía de fuentes bastardas y en transformación constante, "siendo la narración sólo una de ellas" (Minguet, 2001: 26). Los espectáculos de variedades, atracciones, circo o vodevil se entremezclaban con el hecho cinematográfico, caracterizado por una impureza arrolladora que compartirían, casi un siglo después, las heterogéneas salas recreativas de finales de los setenta y comienzos de los ochenta, en las que cabe situar el origen social de los videojuegos. En ambas salas -de juego y de visionado- lo popular y lo lúdico se hermanaban en la efervescencia formal de dos medios todavía en gestación: el cine se mezclaba con otros espectáculos tanto como las máquinas de marcianitos lo hacían con actividades diversas, de la discoteca al futbolín, más allá de marcos prefijados y etiquetas culturales.

Veamos cómo se concretan esas afinidades en el caso de Segundo de Chomón (Garin, 2012a: 297). Es revelador comprobar de qué forma los magos y maestros de ceremonias del primer cine, que con tanta pasión homenajea Marin Scorsese en La invención de Hugo (2011), reproducían a menudo patrones visuales y trucajes que pue- 
blan asimismo las pantallas de los primeros videojuegos. Planos de exploración espacial, que muestran figuras recortables desplazándose sobre un fondo de estrellas (Les lunatiques, 1908), se reencarnan en las pantallas fundacionales de clásicos jugables como Asteroids (1979) o Space Invaders (1978). Sin tramas ni diálogos "que respetar", las imágenes se entregan a la operatividad y buscan fascinar al espectador/jugador en fantasías de gran inventiva visual, un camino abierto a la abstracción, antes de que ambos medios se volviesen más figurativos (Wolf, 2003: 47). No es extraño comprobar que las formas geométricas que dibujan un puñado de acróbatas en Kiriki, acrobates japonais (1907), ante el espectador, sean similares a las que entretejen las piezas en una partida de Tetris (1984), ante el jugador. Puntos de contacto que actualizan el concepto crítico del cine de atracciones: "A cinema that displays visibility, willing to rupture a self enclosed fictional world for a chance to solicit the attention of the spectator" (Gunning, 1990: 57).

Ese buscar la atención del espectador que ocupa a las imágenes es, precisamente, lo que vincula el primer cine con los primeros videojuegos: desentenderse de un propósito "de guión" y entregarse en cambio al aspecto lúdico de lo visual. De hecho, el cine de los orígenes es tan rico en motivos lúdicos que podemos encontrar versiones idénticas de juegos electrónicos entre sus imágenes: sucede en Le théâtre électrique $d u$ Bob (1909), donde dos niños controlan a dos marionetas que se golpean en combate, prefigurando un juego como Street Fighter (1987). La fijación en dispositivos mecánicos, máquinas y autómatas, tan propia de la estética de finales del siglo XIX y principios del XX, entronca con la hibridación tecnológica de los medios interactivos en nuestros días, entre pantallas diversas (Jenkins, 2005: 175). Y muchos de esos protogéneros fílmicos y jugables comparten el estatismo de un tipo de encuadre permanente, fijo, dentro del cual se generan movimientos y transformaciones de índole diversa, que Noël Burch definió como la autarquía del cuadro (Burch, 1999: 193), lo que nos hace ver Le savant et le chimpancé (1900) como un antecedente de Donkey Kong (1981).

\subsection{La estética operacional: del burlesco a los juegos de Super Mario}

Mario Bros es quizá el gran personaje de la cultura popular contemporánea, el único capaz de recoger el testigo que Mickey Mouse heredó de los grandes clowns mudos. Este hecho lo convierte además en un vehículo para entroncar con los intereses de nuevas generaciones de alumnos que, literalmente, se han criado en una cultura del videojuego cercana al universo Nintendo. Para confirmar la popularidad mundial de Mario no hace falta más que recorrer la infinidad de vídeos y fan fictions que emplean imágenes del fontanero en todo tipo de cortometrajes y seriales cómicos en YouTube (Garin, 2012b: 71). El personaje ha sido moldeado a la manera de una estrella del burlesco, con apariciones basadas en la ausencia casi total de narraciones argumentales (como en las bobinas cómicas, donde la trama era una mera excusa) y confiando, en cambio, en el atractivo de su inventiva visual: puras imágenes en movimiento -saltos, lanzamientos , persecuciones- en las que el personaje recorre la pantalla mientras escapa de enemigos ridículos y sortea vertiginosos mecanismos.

Es cierto que hay aspectos clave del cine burlesco que los juegos de Mario ignoran o que apenas han empezado a explorar recientemente -el uso del primer plano, los 
tiempos muertos-, pero pese a ello, pese a que sus juegos no rescaten el realismo callejero y picaresco del slapstick, todo lo que en el cine cómico caía del lado de la fantasía visual, de la geometría, la máquina y la exploración cinética (que era mucho), es reinterpretado de algún modo en las aventuras de Mario. ¿Dónde si no encontramos a un personaje que, como le sucedía a Buster Keaton, permanezca minutos saltando entre plataformas, rotores y balancines, corriendo a toda prisa y sin destino aparente, penetrando en miniaturas hechas pantalla, atravesando paredes, siendo tan sólo un cuerpo (píxel) en movimiento? Esas imágenes, cultivadas por Keaton en sus cortos y perfeccionadas en tratados sobre el movimiento como Siete ocasiones (1925), El moderno Sherlock Holmes (1924) o El héroe del río (1928), esas imágenes que parecían haberse extinguido, son el ADN de las grandes obras maestras de Nintendo, de Super Mario Bros 3 (1988) a Super Mario World (1990), de Super Mario 64 (1996) a Super Smash Bros (1999) y Super Mario Galaxy 2 (2010).

Surge así otro concepto clave de Gameplaygag, la llamada estética operacional que autores como Gunning relacionan con el burlesco y el cine de vanguardia: "This fascination with the way things come together, visualizing cause and effect, through the image of the machine, bridges the end of the nineteenth century and the beggining of the twentieth, shaping many aspects of popular culture" (Gunning, 2003: 75). Se trata de un tipo de audiovisual donde lo que cuentan son los procesos físicos, la cinética de los cuerpos, los mecanismos dentro de la máquina... justo lo que los juegos rescatan del cine cómico mudo. Resulta fundamental recorrer esas cuatro ideas clave actualizándolas en el contexto de la cultura digital contemporánea, pues los juegos de Mario operan precisamente en esa fascinación del funcionamiento (1), de la jugabilidad entre causas y efectos (2), la imagen mecánica (3) y el influjo de la cultura popular (4).

\subsection{El origen de los géneros audiovisuales: de Fairbanks a los beat'em up}

Otra de las dimensiones del proyecto Gameplaygag se centra en la aplicación docente del audiovisual comparado para estudiar la historia de los géneros. El objetivo es ligar conceptos clave de las teorías del género audiovisual a los orígenes del cine mudo y los videojuegos: ideas que, como el genius of the system (Schatz, 1988: 3) o las genre crossroads (Altman, 1999: 199), contribuyen a formar una idea clara en los alumnos acerca de cómo encajan los géneros audiovisuales en el mapa de la producción cultural. Para ello se propone el modelo de trabajo de las películas de Douglas Fairbanks, quintaesencia de la acción-aventura del primer Hollywood, a través del análisis de vídeos a pantalla partida como Fairbanks Action Arcade. Trabajando sobre esos materiales comparados, es posible volver la vista a aquellas películas de aventuras y encontrar una serie de motivos visuales que reaparecen en los primeros juegos de acción y beat'em up. En ambos casos se trabaja el recorrido proteico del personaje, tal y como apuntan los profesores Xavier Pérez y Núria Bou, resaltando la centralidad de la imagen en movimiento como indicador del registro narrativo y genérico (Bou et al., 2000: 28).

Las imágenes y los esfuerzos de trascendencia épica se repiten en ambos medios: el balanceo de Fairbanks agarrado a una cuerda en La marca del Zorro (1920) reaparece en las lianas de Jumpman (1983), y sus escaladas por las paredes sobre la hiedra vuelven en los niveles de Megaman (1987); los saltos por el portón gigante del casti- 
llo de Robin de los bosques (1922) se reencarnan en los muros de Castlevania (1986) y sus flechazos en el arco de Kid Icarus (1986), mientras sus combates aparecen en las peleas callejeras de Double Dragon (1987). Aunque es en El ladrón de Bagdad (1924) donde encontramos una verdadera mina de imaginarios y situaciones que los videojuegos de acción y fantasía retomarían con fuerza, como si los monstruos de cartón piedra de la película permaneciesen en letargo en las catacumbas de Metroid (1986), y las correrías de Fairbanks por el zoco árabe se preservasen en la saga Prince of Persia (1989). Ejemplos de esa cohabitación entre proto-géneros fílmicos y videolúdicos.

\section{Conclusiones: el cine mudo como herramienta de creación interactiva}

Hemos visto las numerosas analogías entre la estética del cine mudo y sus equivalentes en los primeros videojuegos, pero es el momento de plantear la piedra de toque de este análisis: ¿sirve el cine mudo para comprender mejor y, sobre todo, para diseñar videojuegos? Esa pregunta figura como la conclusión o meta del proceso investigador ligado al proyecto Gameplaygag. Between Silent Film and New Media, la puesta a prueba real y práctica de las yuxtaposiciones analizadas hasta este punto.

El trabajo de campo realizado en el EA Game Innovation Lab de la USC, entre Abril y Octubre de 2010, centrado en la realización de entrevistas a creadores de videojuegos, permite concluir que el cine mudo se utiliza actualmente, cada vez más, como una herramienta funcional para la creación de videojuegos. Así lo demuestra el caso del exitoso título The Misadventures of P. B. Winterbottom (2010), cuya estética se basa en el cine burlesco y de los orígenes, adaptando el humorismo visual de Dickens y Gorey, de Méliès, Keaton y Harold Lloyd, a los mandos de control de una videoconsola. Del mismo modo, creadores de primera línea como Warren Spector han empleado imágenes del cartoon y el slapstick en juegos superventas como Epic Mickey (2010), e incluso el flamante ganador del último Premio Príncipe de Asturias de Comunicación y creador de Super Mario, Shigeru Miyamoto, utiliza en los juegos de la saga The Legend of Zelda (1986) los intertítulos mudos, sobre-impresionados en pantalla y sin diálogos sonoros, a la manera del gran cine mudo de Hollywood.

En definitiva, la propuesta de audiovisual comparado aquí presentada (basada en los montajes, vídeos y textos del proyecto Gameplaygag), se sustenta en dos aspectos clave para la mejor comprensión de la historia del audiovisual: por un lado la mirada hacia el pasado, la yuxtaposición de modelos estéticos del cine mudo con sus reflejos y paralelos en los videojuegos; por otro, la mirada hacia el futuro, el legado de aquellos desarrolladores que, a día de hoy, crean juegos que avivan la memoria del primer cine retrospectivamente. Dos grandes cauces que marcan un enfoque docente basado en el remontaje de imágenes y su pensamiento, proclive a la efervescencia de la cultura digital y abierto a sus analogías diferenciales.

\section{Referencias bibliográficas}

ALTMAN, Rick (1999): Film Genre. London, BFI.

BOU, Núria y PÉREZ, Xavier (2000): El tiempo del héroe. Épica y masculinidad en el cine de Hollywood. Barcelona, Paidós. 
GARÍN, Manuel (2008-2012): Gameplaygag. Between Silent Film and New Media: www.gameplaygag.com.

GARÍN, Manuel (2012a): "La fascinació lúdica i participativa: entre Segundo de Chomón i els primers videojocs" en QUINTANA, Ángel y PONS, Jordi: La construcció de l'actualitat en el cinema dels orígens. Girona, Museu del Cinema.

GARÍN, Manuel (2012b): "Super Mario reimaginado. Machinima, glitch y el arte de la apropiación fan en el videojuego" en CARLÓN, Mario y SCOLARI, Carlos Alberto: Colabor_arte. Medios y artes en la era de la producción colaborativa. Buenos Aires, La Crujía.

GUNNING, Tom (1990): “The Cinema of Attraction: Early Film, Its Spectator and the Avant-Garde" en ELSAESSER, Thomas: Early Cinema: Space, Frame, Narrative. London, BFI.

GUNNING, Tom (2003): "Buster Keaton, or the Work of Comedy in the Age of Mechanical Reproduction", en KRUTNIK, Frank: Hollywood comedians. London, Routledge.

JENKINS, Henry (2005): "Games, The New Lively Art", en GOLDSTEIN, Jeffrey y RAESSENS, Joost: Handbook of Computer Game Studies. Boston, The MIT Press.

JENKINS, Henry (2009a): Confronting the Challenges of Participatory Culture. Media Education for the 21st Century. Cambridge, The MIT Press.

JENKINS, Henry (2009b): “The Pickford Paradox", en Confessions of an Aca-Fan: http://henryjenkins.org/2009/08/on_games_and_gags_between_sile.html [consultado el 9 de Octubre de 2012]

KERR, Walter (1990): The Silent Clowns. New York, Da Capo Press.

MANOVICH, Lev (2001): The Language of New Media. Cambridge, The MIT Press.

McKERNAN, Luke (2007-2012): The Bioscope. Reporting on the world of early and silent cinema: www.thebioscope.net.

MINGUET, Joan Maria (2011): Segundo de Chomón. El cinema de la fascinació. Barcelona, ICIC.

SCHATZ, Thomas (1988): The Genius of the System. Hollywood Filmmaking in the Studio Era. New York, Metropolitan Books.

WOLF, Mark J. P.: “Abstraction in the Video Game” en WOLF, Mark J. P.: The Video Game Theory Reader. New York-London, Routledge.

\section{Manuel GARÍN BORONAT}

manuel.garin@upf.edu

Universitat Pompeu Fabra

Departamento de Comunicación

C/ Roc Boronat 138, 08018 Barcelona, España

Profesor Ayudante Doctor 